\title{
An empirical and experiential investigation into the contemplation of joy
}

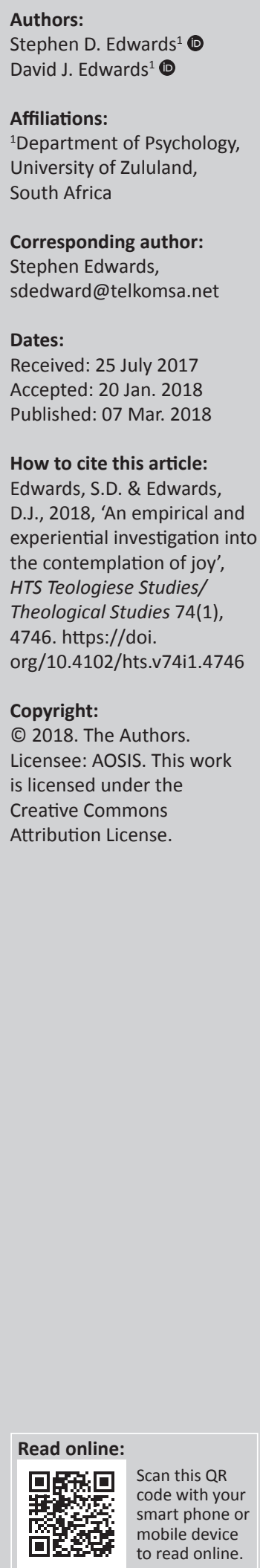

The research was generally motivated by a dearth of studies on joy, and particularly inspired by a book of joy celebrating the inter-spiritual dialogue between the Dalai Lama and Desmond Tutu. Its aim was to investigate whether the direct contemplation of joy would be associated with improvements in psychophysiological coherence, spirituality and various positive emotions and feelings. Integrative quantitative and qualitative findings emerging from a small pilot study, including a convenience sample of six participants with a mean age of 42 years and age range of 25-69 years, supported the research hypothesis. Significant quantitative increases in psychophysiological coherence, spirituality and positive feelings were coherently and consistently supported by participants' individual and collective experiences. Integrative discussion amplified the paradoxical theme of joy through suffering in human emotional and spiritual life.

\section{Introduction}

The global village continually needs healing. Psychoanalytic and other research has provided extensive evidence that much human behaviour is unconscious, irrational and incoherent, reflecting evolutionary survival struggles as well as inadequate nurturing, humanisation, socialisation and consciousness development in general. Moreover, international terrorism, global warming, overpopulation, inequity, unemployment, poverty, illness, injustice, corruption, crime and violence continue to be the order of the day. Although the great major wisdom traditions, including ancestor reverence, Judaism, Hinduism, Buddhism, Taoism, Christianity and Islam (Aurobindo 2011; Mutwa 2003; Wilber 2016), have provided healing for millennia, any global effect is dubious because of continual warring between the traditions themselves. A change in heartfelt coherent consciousness is needed.

This study was motivated by integral, interconnected theoretical perspectives of a transcendent unity of these spiritual and religious traditions (Schuon 1984). This is based on the recognition of a perennial philosophy, a great chain of being or spectrum of consciousness ranging from subconscious to self-conscious and beyond (Huxley 1946; Wilber 2016). It postulates that although initial fundamentalist differences may exist between traditions, ongoing practical inter-spiritual dialogue and coherent co-operation is vitally necessary for planetary survival and healing. The argument amplifies with considerations that international terrorism, for example, often reflects religious divisions, for example, between Christianity and Islam, fuelled by endemic human conflicts, violence, and greed and power motivations. It follows that global healing implies coherent consciousness, care and collaboration by contemporary humanity in their considerable diversity in order to honour and transcend fundamentalist divisions.

The study was particularly inspired by an excellent example of inter-spiritual dialogue in the form of a book of joy celebrating the meeting between Nobel Prize winning leaders of the great spiritual traditions of Buddhism and Christianity, the Dalai Lama and Archbishop Desmond Tutu, as recorded by Douglas Abrams (Lama, Tutu \& Abrams 2016). The auspicious meeting took place in Dharamsala, India. It was originally scheduled to take place in South Africa, but was torpedoed by an unholy international political alliance between Chinese and South African governments. As was the case of Beethoven's great Ode to Joy, these great spiritual leaders explored and produced joyous practices for the benefit of all.

Many great spiritual leaders, such as Merton and Suzuki, embraced the common thread offered by Buddhism and Christianity as well as various other traditions. In addition to their many similarities such as focus on Ubuntu, relationships and transcendence, their relative differences are complementary. Buddhism's practical realism and humanism complements Christianity's 
relatively greater emphasis on the ideal and divine. From a purely inter-spiritual perspective, Buddhism is a practical tradition that resonates with the experience of ordinary humanity, the givens of life and the happiness that develops from embracing these givens (Richo 2005). For example, impermanence offers possibilities for renewal and evolution, suffering opportunities for empathy and compassion.

Positive emotions such as joy are typically interrelated with and interdependent on other emotions and feelings. Lama et al. (2016) quote research that indicates that, in addition to its usual association with such feelings as happiness, contentment, excitement, gratitude and bliss, joy includes exalted states such as spiritual radiance, delight, enchantment and rejoicing in someone else's happiness, called mudita by Buddhists. Wordsworth describes the experience of joy six times in his immortal poem Tintern Abbey, depicting joy in various mystical forms, natural, affective, transcendent and divine. The following two paragraphs are quoted at length as they describe joy as both relief from suffering and ultimate exalted spiritual experience:

... that blessed mood,

In which the burthen of the mystery,

In which the heavy and the weary weight

Of all this unintelligible world

Is lighten'd:- that serene and blessed mood,

In which the affections gently lead us on,

Until, the breath of this corporeal frame,

And even the motion of our human blood

Almost suspended, we are laid asleep

In body, and become a living soul:

While with an eye made quiet by the power

Of harmony, and the deep power of joy,

... And I have felt

A presence that disturbs me with the joy

Of elevated thoughts; a sense sublime

Of something far more deeply interfused,

Whose dwelling is the light of setting suns,

And the round ocean, and the living air,

And the blue sky, and in the mind of man,

A motion and a spirit, that impels

All thinking things, all objects of all thought,

And rolls through all things.

Wordsworth's poetry captures those heartfelt experiences that form the essence of meditation, contemplation, prayer and related healing practices that have formed the coherent core of most major spiritual and wisdom traditions. In addition to such traditional healing practices, contemporary integral scientific views resonate with the phenomenological insights of poets and ancient sages with regard to an integral holism composed of whole or parts or wholes that are part of other wholes that are all defined by the logic of coherence in the patterns displayed, forming resonating settings and interconnecting contexts in a creatively evolving universe (Varela, Thompson \& Rosch 1991; Wilber 2016).

Coherence is the core theme for the Institute of HeartMath concept, a non-profit research and educational organisation, which was established in Boulder Creek, California, in 1991 (Childre \& Martin 1999). In pursuit of a central vision and mission to facilitate personal, social and global coherence, the institute has pioneered integral, heart-focused research in neuroscience, cardiology, physiology, biochemistry, bioelectricity, physics and psychology. This research has enabled the development of practical, heart-based tools and biofeedback technology (Childre et al. 2016) to facilitate heart rate variability (HRV) and psychophysiological coherence and positive emotions such as peace and appreciation.

Although various studies have also provided substantial evidence that HeartMath tools and technology significantly improve the effects of contemplation, meditation and prayer and specifically various positive emotions such as appreciation and peace, to date there has been no specific study on joy. These prompted the research question as to whether the direct contemplation of joy would be associated with quantitative and qualitative improvements in psychophysiological coherence, spirituality and various positive emotions and feelings. In view of the abovementioned evidence, the research hypothesis was chosen over the null hypotheses for any quantitative comparisons.

\section{Method \\ Design}

This small-scale exploratory pilot study required a pre- and post-test, mixed-methods, within-subjects, outcome evaluative design (Creswell \& Plano-Clark 2007; Terre Blanche, Durrheim \& Painter 2006). As specifically inspired by the book on joy, the study is theoretically interdisciplinary, especially concerning spiritual and psychological phenomena relating to Christianity and Buddhism. The specific, applied focus of the investigation concerned a small sample of Christians' experience of joy. In this applied context, it is pastoral theological and psychological in approach.

\section{Participants}

The participants were a small, convenience sample of six volunteer adults, three women and three men, with a mean age of 42.17 years, standard deviation (SD) of 16.79 and age range of 25-69 years. All participants were selected for their commitment to participate in the research and willingness to explore, describe, explicate and articulate their experience. While such qualitative research selection criteria have certain advantages in small scale, evaluative research as the present study, they do present methodological limitations including social desirability, Hawthorn and experimenter effects. 
These limitations can be addressed through further randomised, controlled studies with larger samples in depth qualitative investigations, mixed and integrated studies. Concerning sample size, there is no set sample size for qualitative studies but generally they involve around six to eight people, for homogeneous samples as in the present study, where emphasis is on individual participants' characteristics and/or experiences of the phenomenon or event being researched (Terre Blanche et al. 2006:289). Although larger samples are preferable for purposes of reaching significance levels in statistical analysis of quantitative data, this investigation was essentially qualitative in nature in its concern with contemplation of the experience of joy. The phenomenon or experience of joy is more spiritual and psychological than material, more subjective than objective, more qualitative than quantitative, more concerned with meaning than measurement, with insightful, experience than resulting behaviour or the number of times a certain joyful action may be performed. This does not in any way diminish the great value of the quantitative data in providing material, objective, correlative signatures of the subjective, qualitative data. A final sampling decision to remain with six participants and not to conduct further contemplation sessions was made on the basis of the homogeneity of the sample as well as saturated and integrated nature of the data gathered.

\section{Procedure}

The term 'contemplation' was chosen in preference to 'meditation' for this study for various reasons. Firstly, the term is more popularly and frequently used than meditation in local Christian contexts. Secondly, it is inclusive of meditation and prayer in the Christian recognition that, like everything else, discursive thought and acts of will are gifts received through the grace of God (McGinn 2006:519-520). Thirdly, it is more conventionally Christian, with timehonoured historical roots derived from the Latin word contemplatio, a Catholic, particularly Eastern, Orthodox Church, translation of the Greek theoria, the gospel word for divine vision. Finally, as 'the highest expression of intellectual and spiritual life' (Merton 2006:546), contemplation was considered appropriate for the focus on joy.

After appropriate establishment of rapport and discussion with regard to procedure, all contemplation sessions took place in a relaxed, comfortable and quiet setting. Pre-testing consisted of completion of psychometric measures and $5 \mathrm{~min}$ HeartMath recording in a rest condition. This was followed by instructions to: 'please contemplate joy for at least $20 \mathrm{~min}$. Afterwards you will be asked to describe in writing your contemplation experience'.

\section{Instruments}

Psychophysiological coherence variables were measured on HeartMath tools, Inner Balance and emWave2. When attached to a laptop computer, these give readings of HRV, time elapsed as well as low (LO), medium (ME) and high
(HI) levels of physiological coherence. Feedback consisted of red, blue and green coloured bars with percentage indications and accompanying tones for LO, ME and HI coherence levels, respectively. Further feedback was provided by a cumulative coherence graph with a demarcated area for coherence indicating the zone of optimal autonomic nervous system functioning (Institute of HeartMath 2014).

In addition to the numerous studies providing a rigorous evidence base attesting to the scientific value and effectiveness of the HeartMath system, an independent HeartMath research website: https://scholar.google.com/ci tations? user=frIB6zgAAAAJ\&hl=en, Google Scholar lists 327 independent studies conducted by researchers not employed by or attached to the HeartMath Institute, which provide consistent evidence for the natural, human and social scientific value, validity and effectiveness of the HeartMath system, tools and techniques. This is not surprising when it is considered that these tools and techniques usually involve various procedures based on established physical, biological and psychophysiological evidence related to (1) the physical law of resonance; (2) electromagnetic and cardiorespiratory activity; (3) the 10th cranial or vagus nerve, with its mainly afferent, heart to brain neural communication system including systemic brainstem, limbic, amygdala and prefrontal neural communication networks; (4) respiratory sinus arrhythmia (RSA), the naturally occurring physiological mechanism whereby heart rate increases during inhalation and decreases during exhalation; (5) HRV and related adaptive function of varying intervals between heart beats as well as coherent and incoherent heart rhythms and their correlations with negative emotions and positive emotion, respectively, with the latter heart rhythms resembling coherent sine-wave-type activity and (6) biofeedback principles.

The Spirituality Scale is consisted of a 12-item adaptation of Delaney's (2005) Spirituality Scale. This was standardised with a South African sample of 302 participants and a short 12-item version (SS-12) of the scale was developed (Edwards 2012). Reliability analysis for the SS-12 as a whole indicated a very satisfactory total scale alpha coefficient of 0.82 . Responses to items were scored on a one- to four-point Likert rating system graded from strongly disagree to strongly agree.

The Profile of Mood States is a 65-scale mood scale assessing six factors of tension, depression, anger, vigour, fatigue and confusion. A six-item version has also been found to be a valuable (Dean, Whelan \& Meyers 1990). The present study used an adapted version of this short scale with specific reference to five negative and five positive feeling states. The negative feeling states were: anxious, sad, confused, angry and tired. The positive feeling states were: happy, contented, peaceful, energetic and joyful. Instructions required participants to explore and rate their feelings. Responses to items were scored on a one- to four-point Likert rating system graded from strongly disagree to strongly agree for each 
feeling state. At post-testing, all participants provided written descriptions of their contemplation experiences.

\section{Ethics}

All participants were personal acquaintances, who showed particular interest in the project when approached. They were fully informed as to the nature of the research and provided consent with regard to the use of the information for publication purposes. Participants were guaranteed nominal confidentiality and advised as to their right to withdraw from the research at any stage. Institutional approval was obtained from HeartMath and respective university research committee. Concerning any possible ethical implications, relationship variables are vitally important in small-scale exploratory research, the more trusting and established the relationships, the less inhibition and greater the freedom to explore and share experiences. The fact that the experiences are unique, different as well as similar is a testament to the authenticity and integrity of the study, researchers and participants.

Both authors are certified HeartMath coaches. In this study, this was considered necessary for measurement and intervention purposes and did not indicate conflict of interest as the focus of the HeartMath Institute is to promote such positive emotions as joy and coherent communications as was established between researchers and participants. Certainly, from a critical and reflexive perspective, the exploratory pilot study will have been influenced by the authors' knowledge and experience of HeartMath techniques, tools and interventions. The many limitations of the present study are readily acknowledged. These include its small-scale exploratory nature and lack of a control group. Phenomena such as the placebo, Hawthorne effect and general expectancy and relationship variables will have featured. Further research is needed to generalise and/or transfer findings in different contexts with other participant samples and methods. Randomised controlled studies are recommended to control for possible experimenter effect of enhanced expectancies of participants, who are fully informed as to HeartMath research findings. Such randomised controlled studies are also specifically needed for causal inferences to be postulated with regard to quantitative data.

\section{Data analysis}

The small sample indicated Statistical Package for the Social Sciences (SPSS) non-parametric analysis involving Wilcoxon $Z$ statistics for psychometric comparisons between pre-test and post-test scores for all measures. It should be noted that while non-parametrical statistical techniques are actually based on ranking procedures, only mean score ratings are tabulated for illustrative purposes. The conventional probability level of $p<0.05$ was set for all significant statistical comparisons. Qualitative data in the form of participants' descriptions were thematically content analysed.

\section{Results}

\section{Quantitative physiological coherence and psychological findings}

Table 1 refers to pre-test and post-test means and SD for percentage measures of low medium and high psychophysiological coherence and spirituality scores. The table indicates that there were correspondingly significant decreases in low physiological coherence level: $Z=1.99$, $p=0.046$; medium physiological coherence level: $Z=1.99$, $p=0.046$; with correspondingly significant increase in high physiological coherence level: $Z=1.99, p=0.046$.

These significant psychophysiological coherence and spirituality changes were accompanied by significant decreases in negative feelings $Z=2.21, p=0.027$; and significant increases in positive feelings: $Z=2.10, p=0.028$. Inspection of Table 1 indicates that the significant negative

TABLE 1: Pre-test and post-test means and standard deviations for measures of low, medium and high psychophysiological coherence levels; spirituality perceptions; anxious, sad, confused, angry, tired, happy, contented, peaceful, energetic and joyful feelings as well as total negative and positive feelings (feel) for the various single feeling scores.

\begin{tabular}{|c|c|c|c|c|c|c|}
\hline Measure & Pre-test & SD & Post-test & SD & Wilcoxon Z & Probability \\
\hline LO & 22.33 & 9.79 & 4.33 & 5.35 & 1.99 & 0.046 \\
\hline ME & 27.17 & 11.30 & 10.67 & 11.06 & 1.99 & 0.046 \\
\hline HI & 50.50 & 16.60 & 85.33 & 15.95 & 1.99 & 0.046 \\
\hline Spirituality & 37.67 & 5.31 & 45.67 & 2.70 & 2.20 & 0.027 \\
\hline Anxious & 2.00 & 0.63 & 1.33 & 0.52 & 1.63 & 0.102 \\
\hline Sad & 1.66 & 0.52 & 1.33 & 0.52 & 1.41 & 0.157 \\
\hline Confused & 2.00 & 0.89 & 1.33 & 0.52 & 2.00 & 0.046 \\
\hline Angry & 1.63 & 0.10 & 1.00 & 0.00 & 1.60 & 0.102 \\
\hline Tired & 2.00 & 0.63 & 1.67 & 0.82 & 1.00 & 0.307 \\
\hline Happy & 3.00 & 0.63 & 3.50 & 0.55 & 1.73 & 0.083 \\
\hline Contented & 3.00 & 0.63 & 3.00 & 1.10 & 000 & 1.00 \\
\hline Peaceful & 2.67 & 0.52 & 3.67 & 0.52 & 2.10 & 0.034 \\
\hline Energetic & 2.33 & 0.82 & 2.83 & 1.17 & 1.00 & 0.317 \\
\hline Joyful & 2.67 & 0.82 & 3.50 & 0.55 & 2.24 & 0.025 \\
\hline Positive feel & 13.67 & 2.50 & 17.17 & 2.79 & 2.20 & 0.028 \\
\hline
\end{tabular}

SD, standard deviation; LO, low; ME, medium; HI, high. 
feeling decreases were particularly associated with significant decreases in confused feelings; $Z=2.00, p=0.046$, while the significant positive feeling increases were especially associated with significant increases in peaceful; $Z=2.21, p=$ 0.027 and joyful feelings; $Z=2.20, p=0.028$, respectively. Thus, although numbers are very small, and no great value can be attached to these findings, findings from various measures all provided consistent support for the research hypothesis that the contemplation of joy was associated with high psychophysiological coherence levels, increased spirituality perceptions and positive feelings. This quantitative evidence is supported by participants' descriptions of their experiences as indicated below.

\section{Qualitative findings as reflected in individual participants experiential descriptions}

The six participants' experiences of the contemplation of joy, coded A to F, follow:

A. I contemplated joyful experiences with family members during childhood. There was a sense of shared joy and happiness, free from the constraints and boundaries of day-to-day life. I was reminded of strong connections with people and family events with a warm sense of love.

B. I reflected how my joy comes from my Christian faith and belief in the Father, Son and Holy Spirit. I focused on my beautiful wife and soon to be born child and the blessings that they are. I remembered my childhood and all the enjoyable moments of fishing, paddle skiing and bodyboarding, playing sports such as cricket, hockey, tennis and competing in athletics. I remembered growing up in Africa and what a special place it is, how much I enjoy relaxing and being peaceful. I remembered spending time with family and friends and the wonderful moments that we had. I thought back on the joy I have had from studying and working in some incredible places. During the contemplation whenever my mind wondered, I brought it back to focusing on my Christian faith and how God provides all the joy that happens in my life.

C. My experience today of joy basically was realising my appreciation of God and his gift of life everlasting through his son Jesus and how he constantly guides and forgives when I need to be forgiven and for all he has given me in my life to this point.

D. I felt a great sense of emotion overwhelm me at certain points of contemplation, especially when trying to understand and fully experience the feeling of joy. I often tend to overthink things so being able to relax and focus on joy was a unique experience that filled me with a sense of peace and calm that is foreign to me. I think that there is so much more for me to learn about truly expressing joy in myself and that once I fully understand it on a deeper more spiritual level that my experience will evolve and grow in more profound ways.

E. I concentrated on joyful music and sang in my mind with a choir mostly in church. I heard beautiful music playing in my head and imagined myself driving around the beautiful mountains in the Cape taking in the awesome scenery of the turquoise oceans and blue skies of creation. I imagined my grandson throwing his arms around me when I arrived at the airport in Cape Town with shouts of joy. This brings me utmost joy.

F. I feel at peace, happy, content and excited about life and the journey that I am on. Life is a wonderful experience and I am grateful that I have an opportunity to contribute towards making the world a better place.

\section{Qualitative findings as revealed through thematic content analysis}

From a collective perspective, the following five themes emerged: (1) Spirituality with special reference to religion, Christianity, Church, God, Jesus and Holy Spirit, blessedness, forgiveness, evolution, growth, music and song (Participants A-F). This spirituality theme was coherently and inextricably related to: (2) positive feelings associated with deep emotion, excitement, gratitude, love, freedom, peacefulness, happiness and relaxation (Participants A-F), (3) learning, study, work, life journey and contribution (Participants B, D and F), (4) family relationships, including childhood experiences (Participants A and B) and (5) outdoor and sporting experiences (Participants A and E).

\section{Discussion}

From an integrative perspective, the significant association between joy contemplation and spirituality increases was supported by both quantitative and qualitative findings. Participants variously expressed this in terms of love (A), Christian faith (B), appreciation of God (C), spiritual growth level (D), choir music (E) and various feelings including gratitude (F). Unsurprisingly, in addition to a significant collective decrease in negative feelings, especially confusion, the contemplation of joy was coherently related to the feeling of joy, as well as that of peacefulness. These findings are consistent with rigorous research findings of many studies initiated via the HeartMath Institute (Childre et al. 2016) as well as independent researchers pointing to the significant associative link between psychophysiological coherence and various positive emotions such as happiness, contentment, excitement and peacefulness (Edwards 2016; McCraty \& Rees 2009). Again, it should be emphasised that this was a smallscale exploratory study, findings should be treated with caution, and no final significant conclusions can be drawn. Even in randomised controlled trails with large samples, inferences may be drawn and hypothesis supported, accepted or rejected, but never proved in the strict sense that further studies could always add further as well as deeper truths.

The paradoxical message arising from the Dharamsala meeting between the Dalai Lama and Archbishop Desmond Tutu is that joy is only possible through suffering. Richo (2005) shares a similar message on other givens in life. If accurately perceived and endured, suffering and other givens, including joy, bring opportunities such as healing, acceptance and deeper appreciation. Furthermore, the joy of 
tonglen and kenosis comes from the healing they bring to recipients and practitioners alike. The colloquial phrase amongst oppressed South Africans, which resounded as a clarion call to collective anti-Apartheid mass action, rang: 'an injury to one is an injury to all'. Genuine healers view healing as a resource to be shared, not an endowment to be horded by a select few, as easily becomes the case when greedy practitioners establish artificial political and economic boundaries around healing practices. In such cases, a terrible truth is that medicine readily becomes a commodity rather than a resource.

Although a contemplative session of 20 min duration may be very short compared to the regular 4 and 3 hourly morning meditation sessions of the Dalai Lama and Bishop Tutu, respectively, the findings support the empirical and experiential value of even small doses of such practice with regard to joy in particular. Although contemplation itself constitutes spiritual practice, further studies also need to investigate the value of related action stemming from such contemplation. The ultimate reality of this path of the pilgrim or Arahat, as amplified in spiritual traditions such as Christianity and Buddhism, through the choices of enlightened Saints and Bodhisattvas, whose calling it is to assist the suffering after personally attaining heaven and/or enlightenment. As tersely expressed, in the book on joy, by the Dalai Lama, when faced with a choice between heaven and hell, he would rather go to hell because he could help all those who suffer there.

Some may argue that the source of joy is different between the various religions and others may argue that the source may be different between religions traditions but not across traditions. Firstly, much depends upon the inclusiveness or exclusiveness of the subjects' perception. Secondly, assuming an exclusive perception of source, the source may be different but the experience may be similar if not identical. Thirdly, as perceptions cross spiritual and psychological domains, the source may be more spiritual, but the perceptions more psychological. Finally, there is the view that no exact line can be drawn between source and perceiver. In other words, if source is omnipresent, as is God in Christian theology, this implies that this source is also present (even if minimally) in the perceiver.

As with all well-being, mood and feeling states, joy has both pleasurable and meaningful aspects, as in the hedonistic and eudaimonic distinction. Although participants' experiences were essentially hedonic, deeper undercurrents are also apparent. Participants A and B refer to joyful experiences that occurred in earlier times, Participant $C$ to forgiveness and Participants D, E and F to imagined or future meanings. In this context, Bourgeault (2016) refers to the multivalence in which boundaries distinguishing one emotion from another begin to blend together:

Happiness is tinged with sadness, grief touches at its depths the mysterious upwellings of comfort, loneliness is suffused with intimacy, and the deep ache of yearning for the absent beloved becomes the paradoxical sacrament of presence. (p. 64)
The above-mentioned theme of joy through suffering is only one instance of the multivalent nature of emotional, feeling life that humanity experiences regularly in the everyday dualistic world. Other instances are the pregnant woman who suffers labour to experience the joy of childbirth, the mistakes of sages before enlightenment, the pain of wounded healers, the agony and ecstasy of great artists, the dark night of the soul before transcendence, its release in physical death and ultimate non-duality as in the presence of the risen Christ (McGinn 2006). As Merton pointed out, the dualistic, non-dualistic distinction is itself essentially artificial (Bourgeault 2016).

Finally, from the text of experiential descriptions and deeper intimate silence, joy emerges as a gift of infinite, eternal, immanent and transcendent presence. Depending upon the perceiver, perception, source, cultural and spiritual tradition, this presence has also been variously called emptiness, enlightenment, compassion, grace, the Christ child, divine humanity, light, love and life.

\section{Acknowledgements}

This work is based on research supported by the University of Zululand, South Africa, and the South African National Research Foundation (NRF). Any opinion, finding and conclusion or recommendation expressed in this article is that of the authors and the NRF does not accept any liability in this regard.

\section{Competing interests}

The authors declare that they have no financial or personal relationships which may have inappropriately influenced them in writing this article.

\section{Authors' contributions}

S.D.E., the first author, conceived, researched and wrote the article, and D.J.E., the second author, collaborated on all aspects.

\section{References}

Aurobindo, S., 2011, The integral yoga, Lotus Press, Twin Lakes, WI.

Bourgeault, C., 2016, The heart of centering prayer: Nondual Christianity in theory and practice, Shambala, Boulder, $\mathrm{CO}$

Childre, D.L. \& Martin, H., 1999, The HeartMath solution, Harper Collins, New York.

Childre, D.L., Martin, H., Rozman, D. \& McCraty, R., 2016, Heart intelligence: Connecting with the intuitive guidance of the heart, Waterfront Press, HeartMath, CA.

Creswell, J.W. \& Plano-Clark, V.L., 2007, Designing and conducting mixed methods research, Sage, Thousand Oaks, CA.

Dean, J., Whelan, J.P. \& Meyers, A.W., 1990, An incredibly quick way to assess mood states: The incredibly short POMS, Presented at the Association for the Advancement of Applied Sport Psychology, San Antonio, September.

Delaney, C., 2005, 'The spirituality scale: Development and psychometric testing of a holistic instrument to assess the human spiritual dimension', Journal of Holistic Nursing 23, 1-23. https://doi.org/10.1177/0898010105276180

Edwards, S.D., 2012, 'Standardization of a spirituality scale with a South African sample', Journal of Psychology in Africa 22(4), 655-659.

Edwards, S.D., 2016, 'Influence of HeartMath Quick Coherence Technique on psychophysiological coherence and feeling states', African Journal for Physical Activity and Health Sciences 22(4:1), 1006-1018.

Huxley, A., 1946, The perennial philosophy, Fontana, Glasgow. 
Institute of HeartMath, 2014, Building personal resilience: A handbook for HeartMath certified coachers and mentors, Institute of HeartMath, Boulder Creek, CA

Lama, D., XIV, Tutu, D. \& Abrams, D., 2016, The book of joy: Lasting happiness in a changing world, Avery Publishing, New York.

McCraty, R. \& Rees, R.A., 2009, 'The central role of the heart in generating and sustaining positive emotions', in S. Lopez \& C.R. Snyder (eds.), Oxford handbook of positive psychology, pp. 527-536, Oxford University Press, New York.

McGinn, B., 2006, The essential writings of Christian mysticism, Random House New York.

Merton T., 2006, 'New seeds of contemplation', in B. McGinn (ed.), The essentia writings of Christian mysticism, pp. 545-552, Random House, New York.
Mutwa, V.C., 2003, Zulu shaman: Dreams, prophecies and mysteries, Destiny Books, Rochester, NY.

Richo, D., 2005, The five things we cannot change and the happiness we find in embracing them, Shambhala, Boston, MA.

Schuon, F., 1984, The transcendent unity of religions, Quest Books, Theosophical Publishing House, Wheaton, IL.

Terre Blanche, M. Durrheim, K. \& Painter, D, 2006, Research in practice: Applied methods for the social sciences, University of Cape Town Press, Cape Town.

Varela, F.J., Thompson, E. T. \& Rosch, E., 1991, The embodied mind: Cognitive science and human experience, MIT Press, Cambridge, MA.

Wilber, K., 2016, Integral meditation, Shambhala, Boston, MA 